\title{
INFLUENCE OF CUTTING PARAMETERS ON CHATTER AND TOOL WEAR DURING END MILLING OF STAINLESS STEEL CONDUCTED ON VMC
}

\author{
A.K.M.N. AMIN*, M. IMRAN, AND M. ARIF \\ Department of Mechanical Engineering, Faculty of Engineering, IIUM, Malaysia, Gombak, \\ 53100 Kuala Lumpur, Malaysia. \\ e-mail: akamin@iiu.edu.my
}

\begin{abstract}
Stainless steels are a group of difficult to machine work materials. The difficulty in machining stainless steels is manifested in high contact length and stresses, formation of serrated chips and development of chatter resulting in high tool wear rates and poor machined surface finish. The paper focuses on the performance of TiN coated-carbide inserts in machining stainless steel specimens in end milling operation performed on vertical machining centre (VMC). The performance of the tool is evaluated from the point of view of its wear intensity, mechanism of failure and generation and effect of chatter on tool wear and vice versa. The investigations were aimed at determining the effect of cutting parameters, specifically cutting speed, feed and depth of cut, on chatter amplitude, tool wear rate, mechanism of tool wear and using these data and machined surface roughness values from previous work to come up with recommended values of cutting parameters for semi-finish and finish end milling operation of stainless steel work materials. For recording vibration signals a dual channel portable signal analyzers was used and the signals were analyzed using Pulse Multi-analyzer version 4.2 software. Tool wear was measured using an optical microscope with digital readout capabilities along 3 axes. The tool wear mechanisms were studied under a scanning electron microscope (SEM). Results of the investigation show that acceleration amplitudes generally increase with cutting speed and the magnitude of tool flank wears. It has been also found that an increase in feed and depth of cut leads to higher acceleration amplitudes. The most common wear mechanisms observed during machining of stainless steel are attrition, micro and macro chipping of the tool at lower cutting speeds, and diffusion and mechanical failures due to intensive chatter at higher speeds. It has been also established that stable cutting speeds with relatively low tool wear intensity and satisfactory machined surface finish can be achieved through proper selection of cutting parameters. A table of recommended cutting conditions has been developed for almost chatter free machining with low tool wear intensity and satisfactory surface finish.
\end{abstract}

Key Words: Vertical Machining Centre, Machinability, Chatter, Cutting, Tool life.

\footnotetext{
${ }^{*}$ Contacting Author
} 


\section{INTRODUCTION}

The metal cutting process involves large plastic deformation of the work material ahead of the tool tip and frictional conditions at the shear zone and chip-tool interface. Major portion of the work of plastic deformation and friction is converted into heat, developing very high temperatures at the chip-tool interface, resulting in high tool wear rates and premature tool failures. During machining of high strength materials the situation is even worse. One of the causes of poor machinability of austenitic stainless steel, alloys of titanium and nickel and some aluminum alloys is the formation of serrated chips and appearance of chatter [1,2]. Chatter is a type of self-excited vibration. It results in low machine tools life, poor surface finish and high rate of tool wear. It was found earlier [2,3] and confirmed by recent investigations that the chip formation process is unstable for most metals and their alloys due to the formation of serrated chips $[1,3]$. When the frequencies of formative cycles of these chip elements grow close to the natural frequencies of the individual components of the machine-tool-fixture system, resonance occurs [1,2,4]. It has been also established that during resonance the amplitude of vibration increases to a maximum value and then gradually decreases but the frequency of vibration remains practically constant [2]. Chatter effects can be minimized by appropriate selection of the parameters of the elastic system of the machine-tool-fixture system [2,4] and also cutting parameters. One of the effective ways of controlling chatter is by changing the spindle speed [5].

Among the mechanism of wear observed during machining of stainless steels are attrition, diffusion, abrasion and chipping. It is important to study the mechanism of tool wear under a given set of cutting conditions to be able to predict remedial measures to eliminate the causes of tool failure and at the same time to enhance surface finish and avoid chatter.

The investigations were aimed at determining the effect of cutting parameters, specifically cutting speed, feed and depth of cut, on chatter amplitude, tool wear rate, mechanism of tool wear and using these data and machined surface roughness values from previous work to come up with recommended values of cutting parameters for semi-finish and finish end milling operation of stainless steel work materials.

\section{METHODOLOGY}

Experiments were conducted on Vertical Machining Centre (VMC) model MCFV 1060 LR with Acromatic PC2100 controller. A $32 \mathrm{~mm}$ Weldon type tool holder was used in machining the stainless steel work pieces. The types of the inserts used were Sandvik TiN coated-carbide end milling insert with PM 4040 code. The tool geometry and specifications of the inserts are shown in Fig. 1.

Dual Channel Portable Signal Analyzers Type 2148 (Bruel \& Kjaer) was used in recording vibration signals coming from accelerometer type signal transducers. Analysis of these signals was conducted using Pulse Multi-Analyzer version 4.2 software. The model of the optical microscope used for tool wear measurement was HISOMET DH Series with magnification of $5 \mathrm{x}$ to 40x and digital readout of the $\mathrm{X}, \mathrm{Y}$ and $\mathrm{Z}$ axes traverses. The initial dimensions $(\mathrm{mm})$ of the work materials were as follow: 
Length $\mathrm{x}$ width $\times$ thickness $=300 \times 200 \times 50 \mathrm{~mm}$. The average hardness of the work materials was 93.47 HRB. Cutting conditions are given in Table 1. For each of these cases the following four cutting speeds, (m/min), were used: 90, 110, 130 and 150.

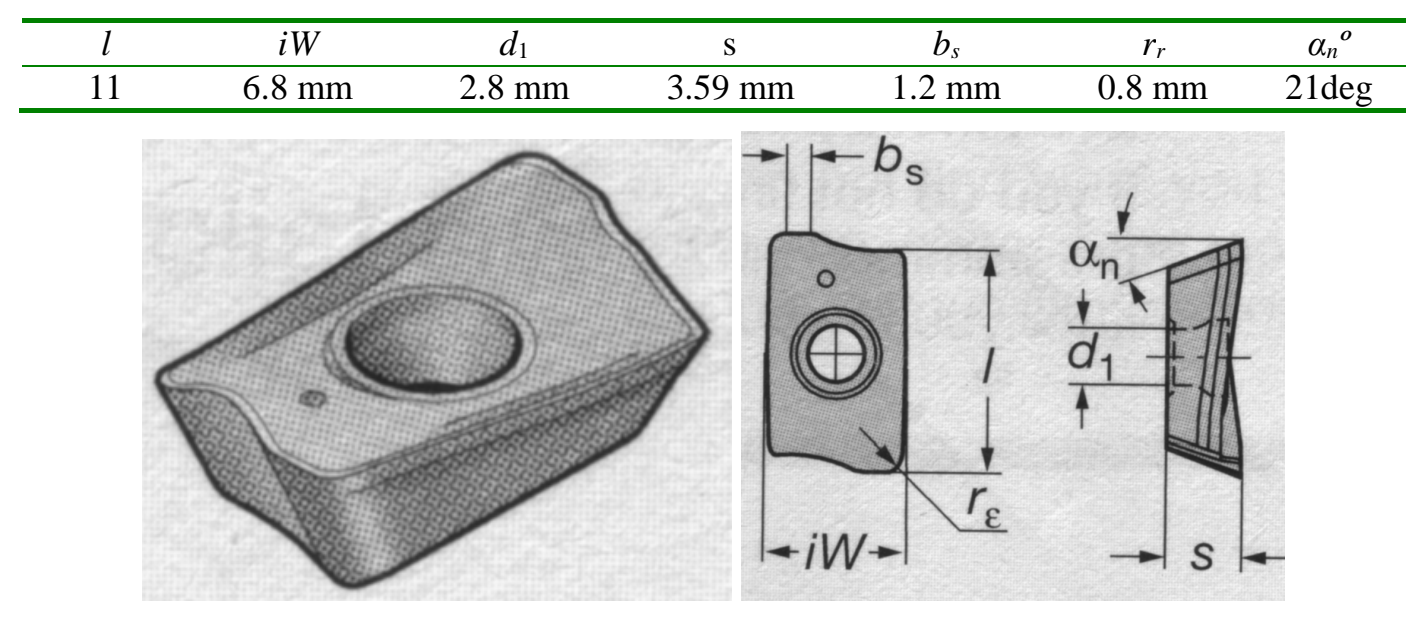

Fig. 1: Insert geometry used in machining.

Table 1: Classification of cases according to cutting parameters.

\begin{tabular}{|c|c|c|c|}
\hline & & \multicolumn{2}{|c|}{ Feed rate $(\mathrm{mm} /$ tooth$)$} \\
\hline & & 0.1 & 0.2 \\
\hline \multirow{2}{*}{ 흘 } & 1 & Cutting Condition I & Cutting Condition III \\
\hline & 2 & Cutting Condition II & Cutting Condition IV \\
\hline
\end{tabular}

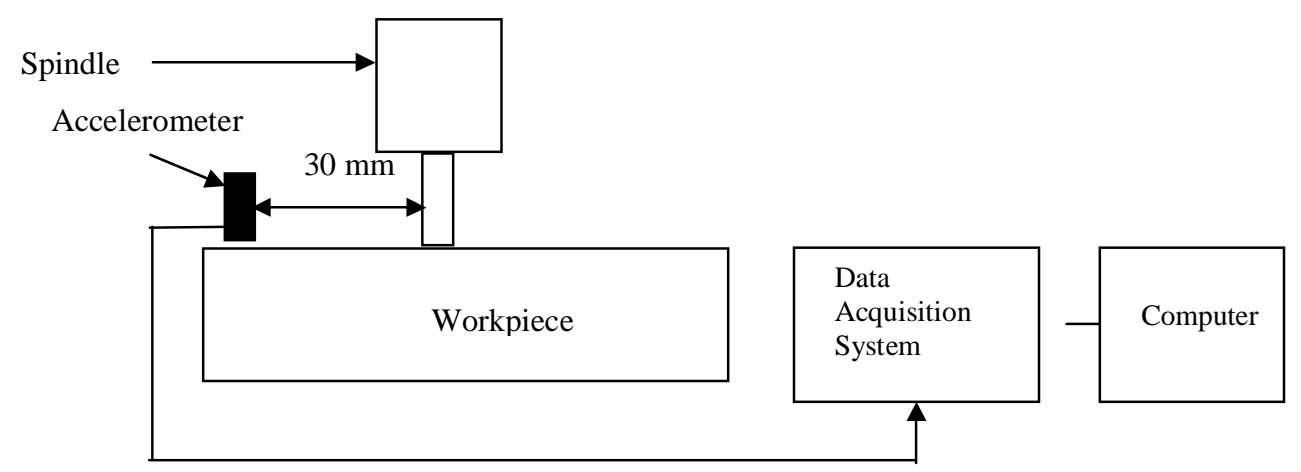

Fig. 2: Block diagram of the experiment setup 
The experimental setup is shown in Fig. 2. The accelerometer for collecting vibration data was placed approximately $30 \mathrm{~mm}$ away from the spindle. Tool wear values were measured for each of the four cutting conditions. At the end of cutting operations the inserts were observed under Scanning Electron Microscope (SEM) model JSM-T330 to study the mechanism of tool wear.

The vibration signals are analyzed to determine the maximum peak amplitudes in two frequency ranges $401-600 \mathrm{~Hz}$ and $601-1000 \mathrm{~Hz}$ since the most chatter peaks are located in this frequency range for end milling, as established by the earlier works of Salha and Salhana [6]. The maximum amplitude values in these two ranges are plotted against cutting speed to represent the dynamic condition of cutting. A maximum value of $18.00 \mathrm{~mm} / \mathrm{sec}^{2}$ has been set as limiting value of chatter amplitude for any recommended cutting condition [6]. Tool wear intensity and tool life values are calculated from the tool wear data. Tool life was calculated on the basis of a tool flank wear of $0.30 \mathrm{~mm}$ as recommended by the ISO standard. Tool wear intensity and tool life diagrams are plotted for analysis for all the cutting conditions. A maximum tool wear intensity value of $7.00 \mathrm{E}-5 \mathrm{~mm} / \mathrm{m}$ has been set as a condition for any recommended cutting condition. Surface roughness data for identical machining condition has been taken from Salha and Salhana's work [6], to complete the recommendation table.

\section{RESULTS AND DISCUSSION}

\subsection{Cutting Condition I (Depth of cut $1 \mathrm{~mm}$ and feed $0.1 \mathrm{~mm} /$ rotation)}

The tool wear intensity curves against cutting speed for all the four cutting conditions are shown in Fig. 3. For cutting condition I two depressions in the tool wear intensity curves are observed at $110 \mathrm{~m} / \mathrm{min}$ and $150 \mathrm{~m} / \mathrm{min}$. Tool wear intensity decreases from $6.91 \mathrm{E}-05 \mathrm{~mm} / \mathrm{m}$ at $90 \mathrm{~m} / \mathrm{min}$ to $3.04 \mathrm{E}-05 \mathrm{~mm} / \mathrm{m}$ at $110 \mathrm{~m} / \mathrm{min}$, then increases to $4.79 \mathrm{E}-05 \mathrm{~mm} / \mathrm{m}$ at $130 \mathrm{~m} / \mathrm{min}$ and decreases back to $3.04 \mathrm{E}-05 \mathrm{~mm} / \mathrm{m}$ at $150 \mathrm{~m} / \mathrm{min}$. The tool life curves against cutting speed in log-log scale for all the four cutting conditions are shown in Fig. 4. From the figure it is observed that tool life for cutting condition I decreases very slowly with cutting speed. The curves of acceleration amplitude versus cutting speed (Fig. 5) shows that, the maximum acceleration amplitude for $401-600 \mathrm{~Hz}$ and $601-1000 \mathrm{~Hz}$ ranges occur at $130 \mathrm{~m} / \mathrm{min}$. The amplitude values are quite low in the remaining three cutting speed (close to or below $18 \mathrm{~mm} / \mathrm{sec}^{2}$ ). The SEM diagrams of the tools taken at the end of machining for cutting condition I are shown in Fig. 6(a-d). Common wear mechanisms observed at all the speeds are micro chipping of the tool due to attrition and diffusion wear. Diffusion wear occurs by a solid-state diffusion mechanism and the rate of diffusion is dependent on the ambient temperature and increase in temperature causes exponential increases in the rate of diffusion. Figure 3 and Figure 6(a-d) also indicate that the average intensities of wear of the tool are low at $110 \mathrm{~m} / \mathrm{min}$ and $150 \mathrm{~m} / \mathrm{min}$ and within acceptable limits. Since the amplitude of chatter, intensity of tool wear and surface roughness are low at $110 \mathrm{~m} / \mathrm{min}$ and $150 \mathrm{~m} / \mathrm{min}$, these two cutting speeds may be recommended for machining for this cutting condition, as shown in Table 2. Speed $130 \mathrm{~m} / \mathrm{min}$ being the higher of the two speeds would result in higher productivity and lower cost, though at this speed the amplitude level of chatter slightly exceeds the recommended maximum value of $18.0 \mathrm{~mm} / \mathrm{sec}^{2}\left(18.6 \mathrm{~mm} / \mathrm{sec}^{2}\right)$. 
Table 2: Recommended cutting conditions for stainless steel.

\begin{tabular}{|c|c|c|c|c|}
\hline \multirow{3}{*}{$\begin{array}{c}\text { Speed } \\
\text { (m/min) }\end{array}$} & \multicolumn{2}{|c|}{ Feed $0.1 \mathrm{~mm} /$ tooth } & \multicolumn{2}{|c|}{ Feed $0.2 \mathrm{~mm} /$ tooth } \\
\hline & \multicolumn{4}{|c|}{ Depth of Cut } \\
\hline & $1 \mathrm{~mm}$ & $2 \mathrm{~mm}$ & $1 \mathrm{~mm}$ & $2 \mathrm{~mm}$ \\
\hline \multirow[t]{3}{*}{90} & $6.91 E-05$ & $6.63 E-05$ & $10.68 \mathrm{E}-05$ & $8.31 \mathrm{E}-05$ \\
\hline & 14.2 & 21.5 & 23.33 & 24 \\
\hline & 0.29 & 0.33 & 1.16 & 0.56 \\
\hline \multirow[t]{3}{*}{110} & $3.04 E-05$ & $3.78 E-05$ & $6.82 E-05$ & $7.18 \mathrm{E}-05$ \\
\hline & 16.3 & 17.3 & 16.6 & 23.7 \\
\hline & 0.24 & 0.31 & 0.91 & 0.65 \\
\hline \multirow[t]{3}{*}{130} & $4.79 E-05$ & $4.24 E-05$ & $9.39 \mathrm{E}-05$ & $6.40 E-05$ \\
\hline & 25.1 & 21.8 & 27.5 & 28.2 \\
\hline & NA & NA & NA & NA \\
\hline \multirow[t]{3}{*}{150} & $3.04 E-05$ & $4.24 E-05$ & $8.11 \mathrm{E}-05$ & 8.84 E-05 \\
\hline & 18.7 & 24.6 & 29.8 & 26.8 \\
\hline & 0.26 & 0.28 & 1.40 & 0.58 \\
\hline
\end{tabular}

- The upper most value in each cell is tool wear intensity value $(\mathrm{mm} / \mathrm{m})$.

- The second value is maximum acceleration amplitude value $\left(\mathrm{mm} / \mathrm{s}^{2}\right)$.

- The third value is surface roughness $\mathrm{Ra}(\mu \mathrm{m})$.

- Shaded cells are recommended cutting conditions.

- Italic Bold Faced Values: Acceptable Tool Wear Intensity $\left(7.00 \times 10^{-5} \mathrm{~mm} / \mathrm{m} \leq\right)$.

- Italic Values: Acceptable Maximum Acceleration Amplitude Values $\left(18 \mathrm{~mm} / \mathrm{s}^{2}\right.$ $\leq)$ [6].

- Bold Faced Values: Acceptable Surface Roughness (0.1 - 1.6 $\mu \mathrm{m})$ [6]. 


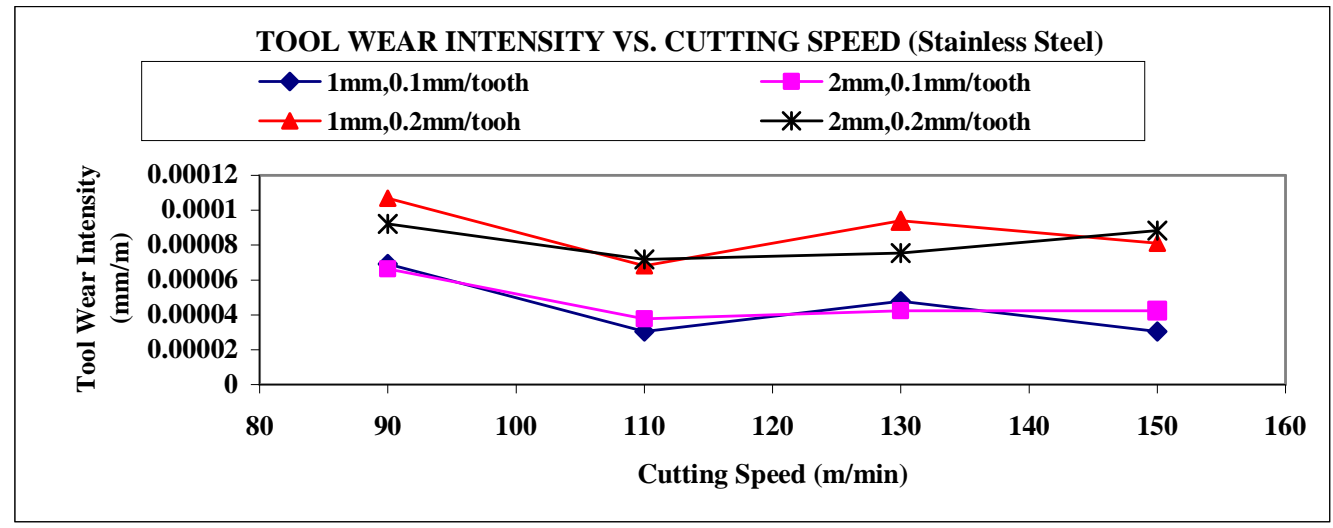

Fig. 3: Influence of the cutting speeds on tool wear intensity for various cutting conditions.

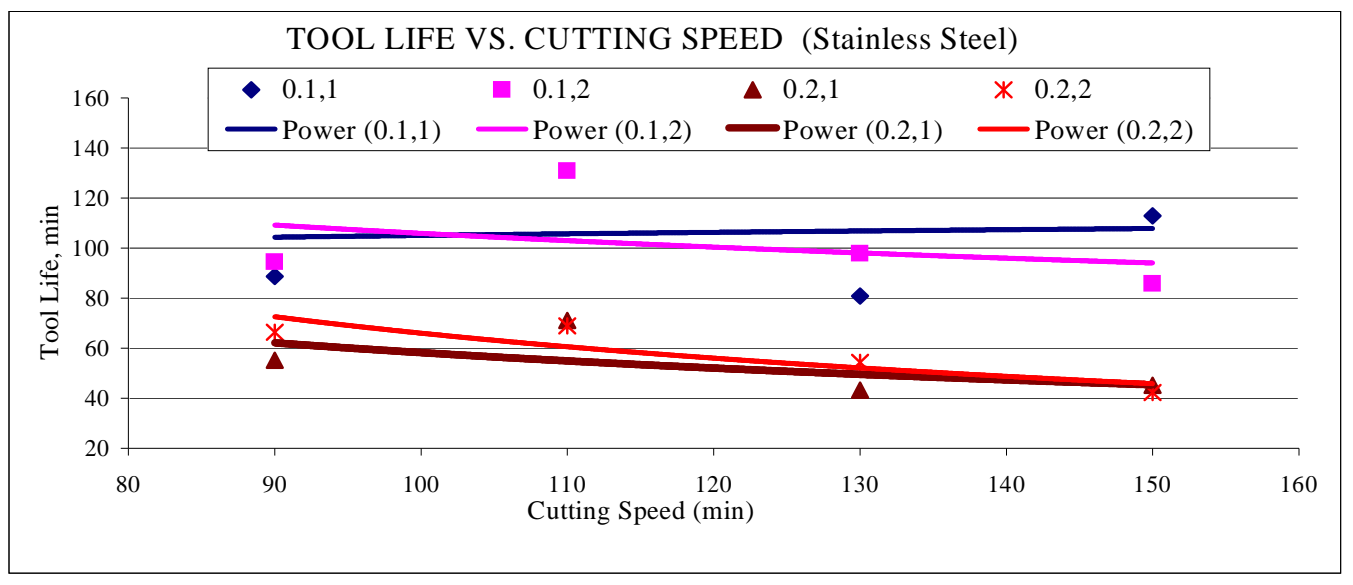

Fig. 4: Tool life of different the cutting speeds for four different cutting conditions.

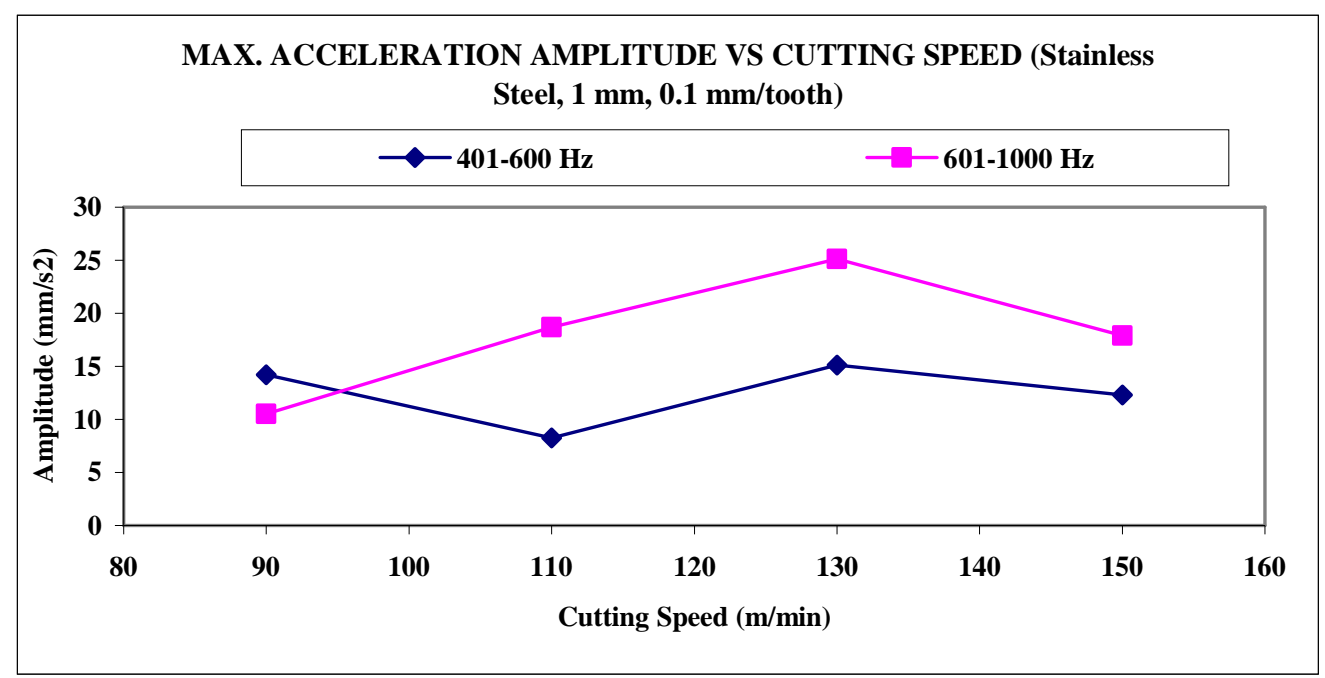

Fig. 5: Influence of the cutting speeds on peak Acceleration Amplitude in the two frequency ranges for cutting condition I. 


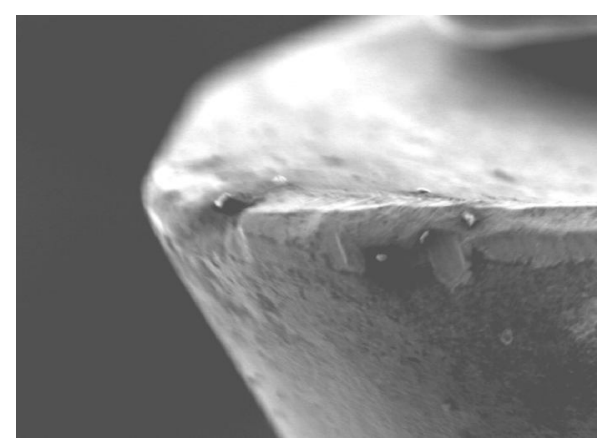

Fig. 6a: Wear experienced at $90 \mathrm{~m} / \mathrm{min}$ of case I ( $95 \mathrm{x}$ enlargement).

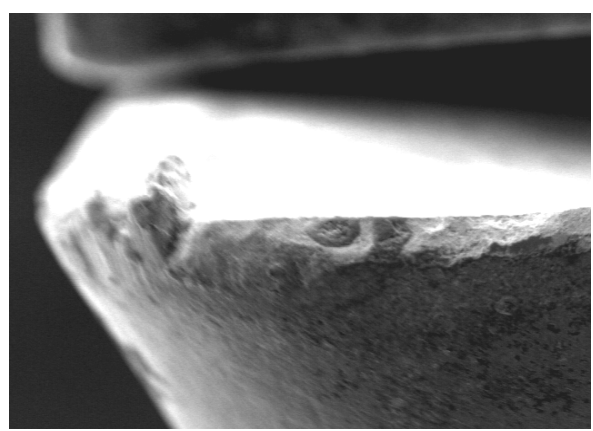

Fig. 6b: Wear experienced at $110 \mathrm{~m} / \mathrm{min}$ of case I ( $95 \mathrm{x}$ enlargement).

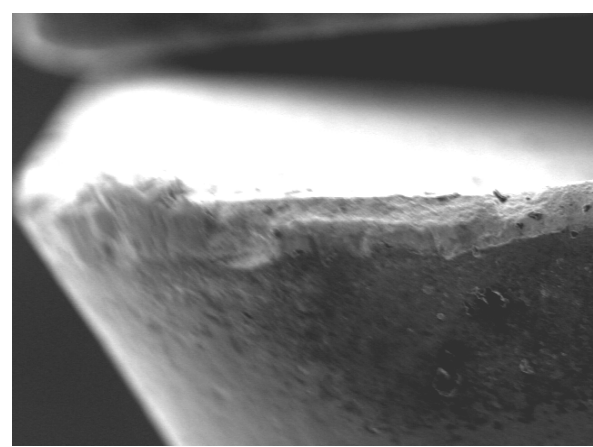

Fig. 6c: Wear experienced at $130 \mathrm{~m} / \mathrm{min}$ of case I (95 x enlargement).

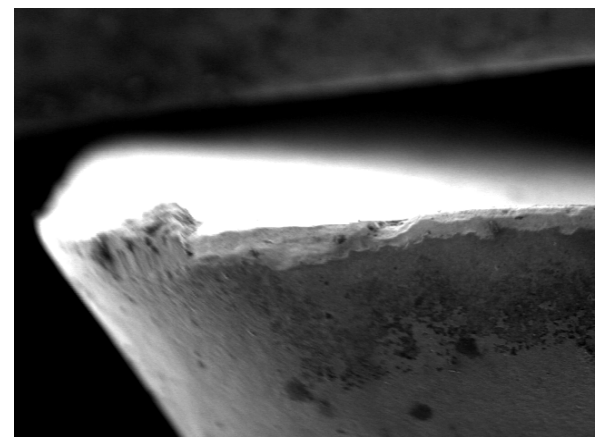

Fig. 6d: Wear experienced at $150 \mathrm{~m} / \mathrm{min}$ of case I ( $95 \mathrm{x}$ enlargement). 


\subsection{Cutting Condition II (Depth of cut $2 \mathrm{~mm}$ and feed $0.1 \mathrm{~mm} /$ rotation)}

For this cutting condition the lowest tool wear intensity of $3.78 \mathrm{E}-05 \mathrm{~mm} / \mathrm{m}$ is observed at $110 \mathrm{~m} / \mathrm{min}$ (Fig. 3). Wear intensity decreases from $90 \mathrm{~m} / \mathrm{min}$ to 110 $\mathrm{m} / \mathrm{min}$ and then increases slightly and stands almost at a constant level (4.24 E-05 $\mathrm{mm} / \mathrm{m}$ ) at $130 \mathrm{~m} / \mathrm{min}$ and $150 \mathrm{~m} / \mathrm{min}$.

Moreover slower decreases in the tool life curve are observed for cutting conditions I and II as compared to the other two cutting conditions. Maximum values of peak acceleration amplitude versus cutting speed graph for both the frequency ranges are shown in Fig. 7. The peak acceleration amplitudes for the frequency ranges of 401$600 \mathrm{~Hz}$ and the $601-1000 \mathrm{~Hz}$ are found to be the minimum at $110 \mathrm{~m} / \mathrm{min}$. It is also observed that the cutting speed of $110 \mathrm{~m} / \mathrm{min}$ with the lowest average acceleration amplitude also offers the lowest tool wear intensity.

The amplitudes of chatter in the two frequency ranges are within satisfactory limit only for this cutting speed (Fig. 7 and Table 2). As also observed from Fig. 8(a-d) the type of tool wear observed at $100 \mathrm{~m} / \mathrm{min}$ is very smooth and no micro chipping is observed. The main mechanism of wear appears to be diffusion. Higher and uneven tool wear was observed at $130 \mathrm{~m} / \mathrm{min}$ and $150 \mathrm{~m} / \mathrm{min}$, which may be due to higher amplitude of chatter. The values of surface roughness attained are acceptable at all four cutting speeds. From all these considerations cutting speed of $110 \mathrm{~m} / \mathrm{min}$ has been recommended for application with these cutting conditions (Table 2).

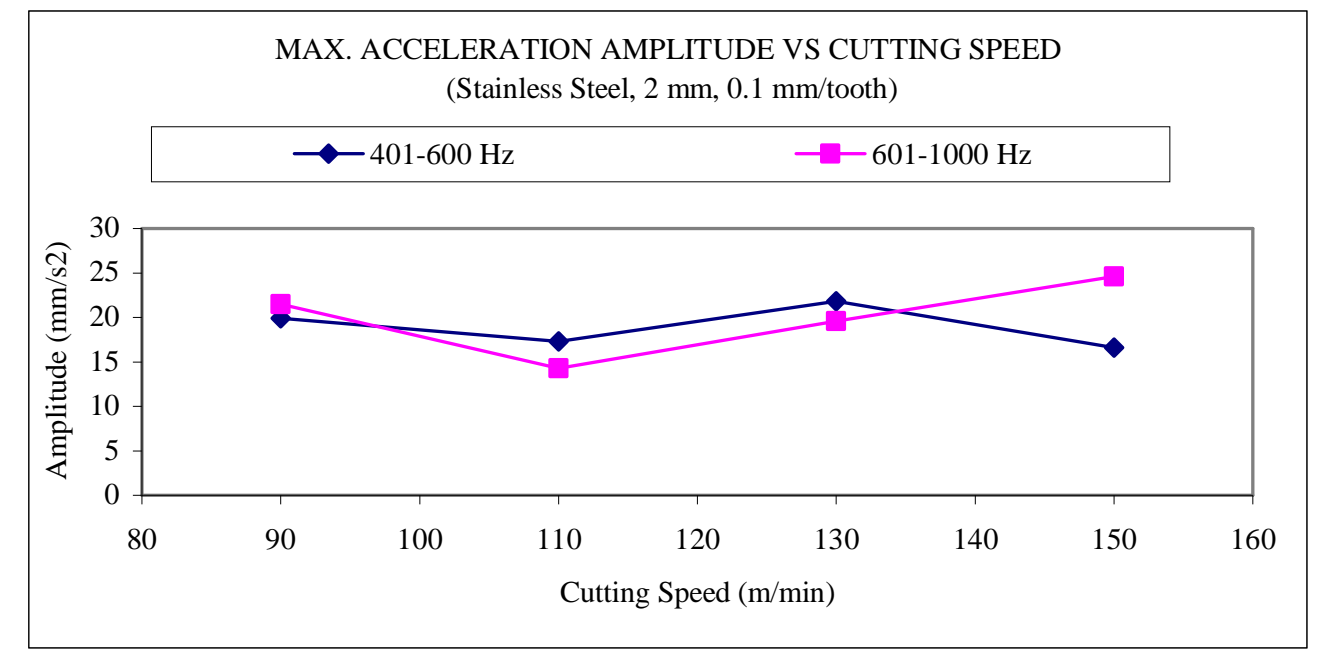

Fig. 7: Influence of the cutting speeds on Peak Acceleration Amplitude in the two frequency ranges for cutting condition II.

\subsection{Cutting Condition III (Depth of cut $1 \mathrm{~mm}$ and feed $0.2 \mathrm{~mm} /$ rotation)}

From Fig. 3 it can be observed that the lowest tool wear intensity in this case is again at $110 \mathrm{~m} / \mathrm{min}$. Tool wear intensity decreases from $10.68 \mathrm{E}-05 \mathrm{~mm} / \mathrm{m}$ at 90 to $6.82 \mathrm{E}$ $05 \mathrm{~mm} / \mathrm{m}$ at $110 \mathrm{~m} / \mathrm{min}$, then increase to $9.39 \mathrm{E}-05 \mathrm{~mm} / \mathrm{m}$ at $130 \mathrm{~m} / \mathrm{min}$ and decreases back to $8.11 \mathrm{E}-05 \mathrm{~mm} / \mathrm{m}$ at $150 \mathrm{~m} / \mathrm{min}$. Tool life curve experiences a sharp 
fall with the increase in cutting speed increase with a deviation at $110 \mathrm{~m} / \mathrm{min}$ (Fig. 4). The fall in tool life for this cutting condition is sharper than in the previous two cases. Maximum acceleration amplitude over cutting speed graphs for both the frequency ranges are shown in Fig. 9. It is observed from the graph that the maximum acceleration amplitudes in the $601-1000 \mathrm{~Hz}$ range are higher than those in $401-$ $600 \mathrm{~Hz}$ range. The minimum amplitude value of $16.6 \mathrm{~mm} / \mathrm{sec}^{2}$ for this range is observed at $110 \mathrm{~m} / \mathrm{min}$. The amplitude value for the other range is also low. The SEM views of the tool, as shown in Fig. 10(a-d), reveal that the tool has experienced brittle failures at all three speeds except at $110 \mathrm{~m} / \mathrm{min}$. At $90 \mathrm{~m} / \mathrm{min}$ the failure is mainly due to attrition and mechanical failures, but at $130 \mathrm{~m} / \mathrm{min}$ and $150 \mathrm{~m} / \mathrm{min}$ the failures are mainly caused by micro chipping, caused by higher amplitudes of chatter, especially in the $601-1000 \mathrm{~Hz}$ range.

\subsection{Cutting condition IV (Depth of cut $2 \mathrm{~mm}$ and feed $0.2 \mathrm{~mm} /$ rotation)}

In this cutting condition the tool wear intensity decreases from $8.31 \mathrm{E}-05 \mathrm{~mm} / \mathrm{m}$ at 90 to $7.18 \mathrm{E}-05 \mathrm{~mm} / \mathrm{m}$ at $110 \mathrm{~m} / \mathrm{min}$ and further to $6.40 \mathrm{E}-05 \mathrm{~mm} / \mathrm{m}$ at $130 \mathrm{~m} / \mathrm{m}$ and then increases to $8.84 \mathrm{E}-05 \mathrm{~mm} / \mathrm{m}$ at $150 \mathrm{~m} / \mathrm{min}$. Tool life also experiences a decreasing trend (Fig. 4). Maximum acceleration amplitude over cutting speed graph for both the frequency ranges are shown in Fig. 11. It is observed from Fig. 11 and Table 3 that the acceleration amplitudes are very high at all the cutting speeds and beyond acceptable limits. The highest maximum acceleration amplitude is found to be at $150 \mathrm{~m} / \mathrm{min}$ for $401-600 \mathrm{~Hz}$ and at $130 \mathrm{~m} / \mathrm{min}$ for $601-1000 \mathrm{~Hz}$. The tool wear intensities are also quite high for all the cutting speeds except $130 \mathrm{~m} / \mathrm{min}$. It is observed from Fig. 12 (a-d) that though the intensity of tool wear is quite high at 90 $\mathrm{m} / \mathrm{min}$, the type of wear is very uniform. So is the case at $130 \mathrm{~m} / \mathrm{min}$. There are some brittle breakages at $110 \mathrm{~m} / \mathrm{min}$, and very intensive and unacceptable tool failure at $150 \mathrm{~m} / \mathrm{min}$. The surface roughness values however, are acceptable in all the cutting speeds (the surface roughness data for $130 \mathrm{~m} / \mathrm{min}$ were not available).

Higher tool wear intensities in most cases of this cutting condition may be due to higher vibration levels during machining and also due to higher amount of attrition wear. So, from the considerations of tool wear intensity and surface roughness, cutting speeds of $90 \mathrm{~m} / \mathrm{min}$ and $130 \mathrm{~m} / \mathrm{min}$ can be applied, though these speeds are not shown as recommended values in Table 2 due to the high amplitude of acceleration at these two speeds.

The lowest tool wear intensity for the three out of the four cases is found to be at 110 $\mathrm{m} / \mathrm{min}$ (Fig. 4). Tool failure is caused mainly due to attrition wear at lower cutting speeds. At higher speeds diffusion wear predominates the other wear mechanisms. At low cutting speeds surface roughness values are also quite poor and the production rates is also low. As such it is not very economical to apply low cutting speeds during stainless steel machining. Tool wear intensities at cutting speeds higher than 110 $\mathrm{m} / \mathrm{min}$ are higher because of rates of diffusion wear at higher speeds, on one hand, and due to higher amplitude of vibrations, on the other hand. Therefore, cutting speeds should be selected in compliance with the criteria set for the selection (Table 2). 


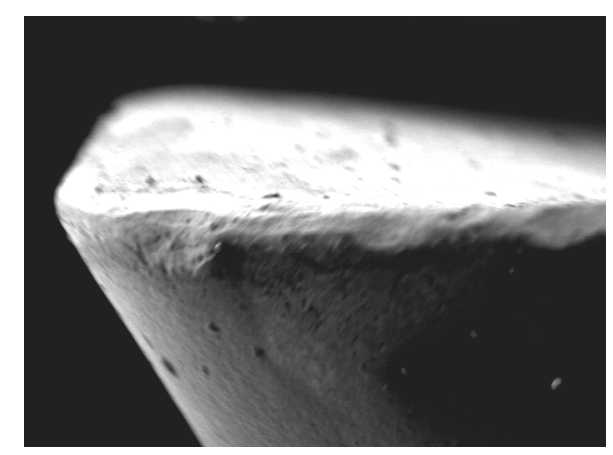

Fig. 8a: Wear experienced at $90 \mathrm{~m} / \mathrm{min}$ of case II ( $95 \mathrm{x}$ enlargement).

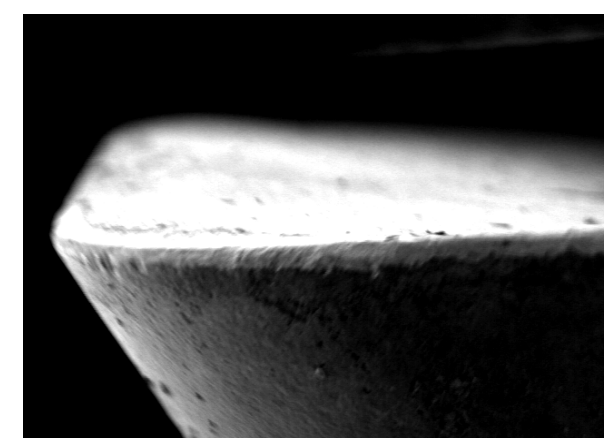

Fig. 8b: Wear experienced at $110 \mathrm{~m} / \mathrm{min}$ of case II (95 x enlargement).

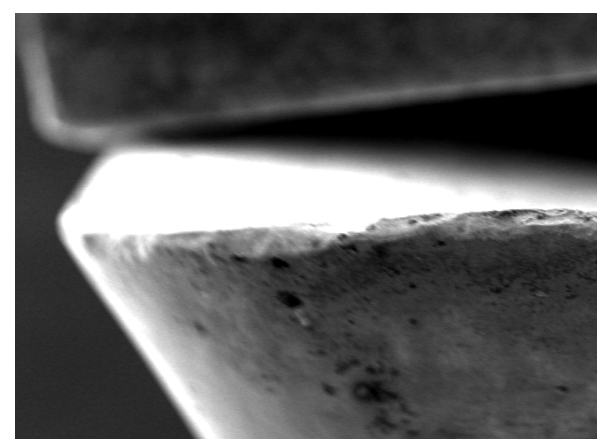

Fig. 8c: Wear experienced at $130 \mathrm{~m} / \mathrm{min}$ of case II (95 x enlargement).

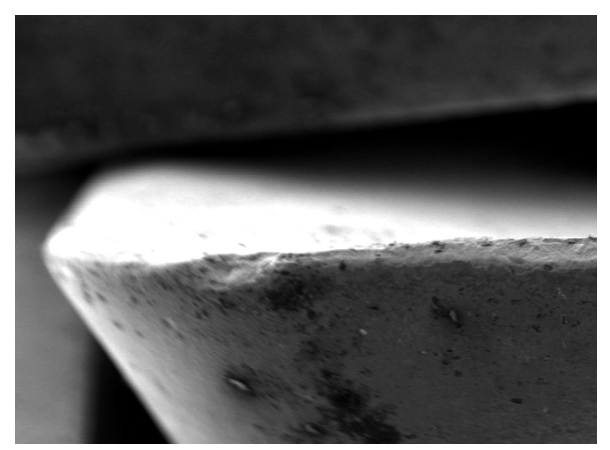

Fig. 8d: Wear experienced at $150 \mathrm{~m} / \mathrm{min}$ of case II (95 x enlargement). 


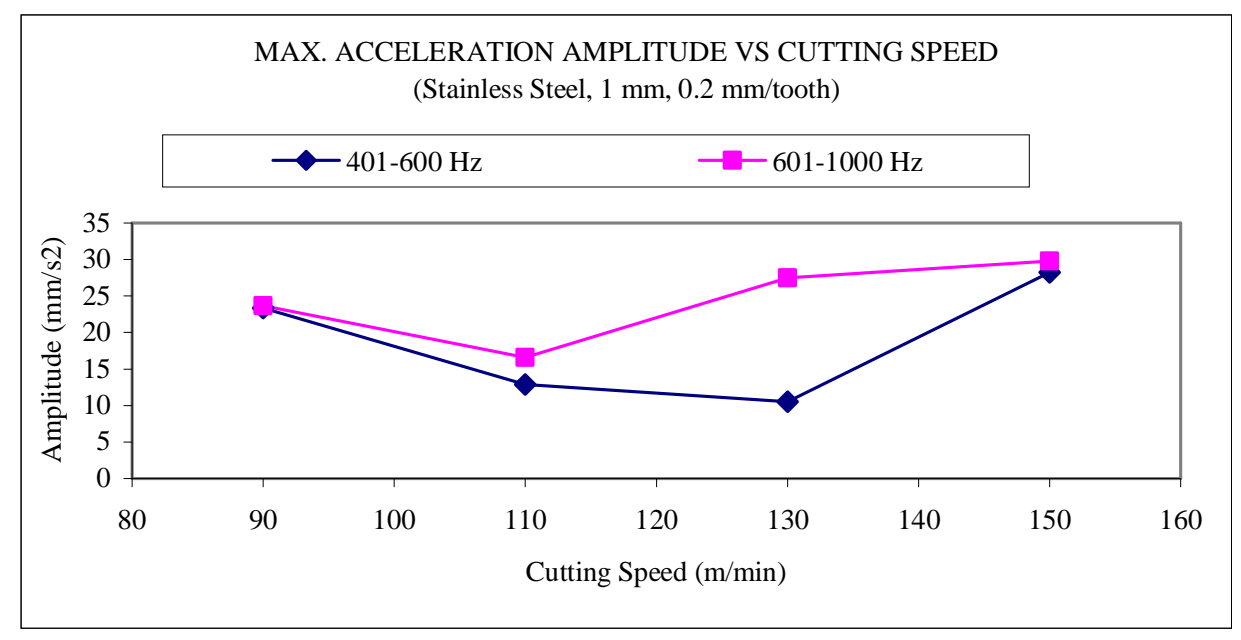

Fig. 9: Influence of the cutting speeds on Peak Acceleration Amplitude in the two frequency ranges for cutting condition III.

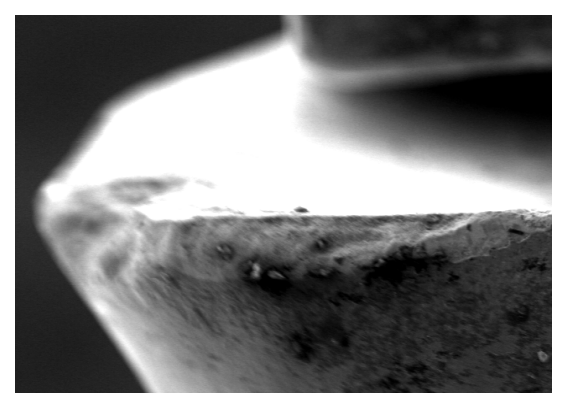

Fig 10a: Wear experienced at $90 \mathrm{~m} / \mathrm{min}$ of case III ( $95 \mathrm{x}$ enlargement).

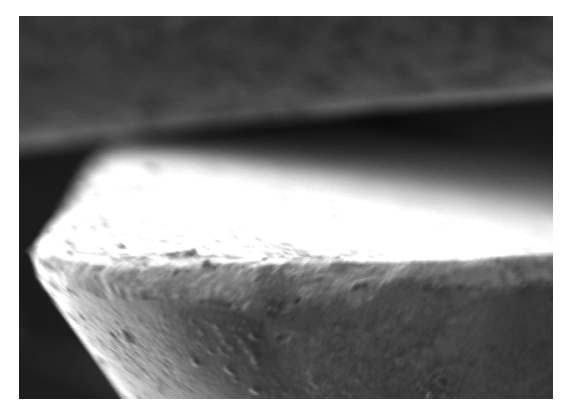

Fig. 10b: Wear experienced at $110 \mathrm{~m} / \mathrm{min}$ of case III (95 x enlargement).

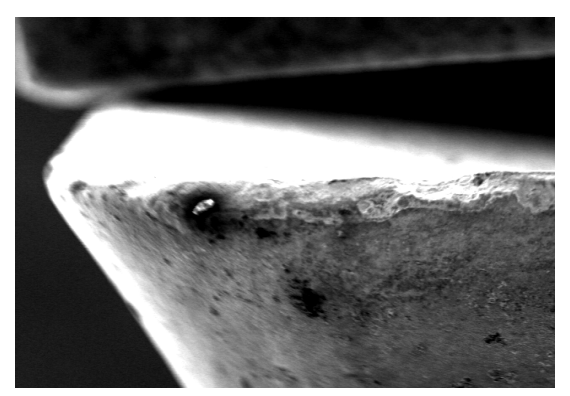

Fig. 10c: Wear experienced at $130 \mathrm{~m} / \mathrm{min}$ of case III (95 x enlargement). 


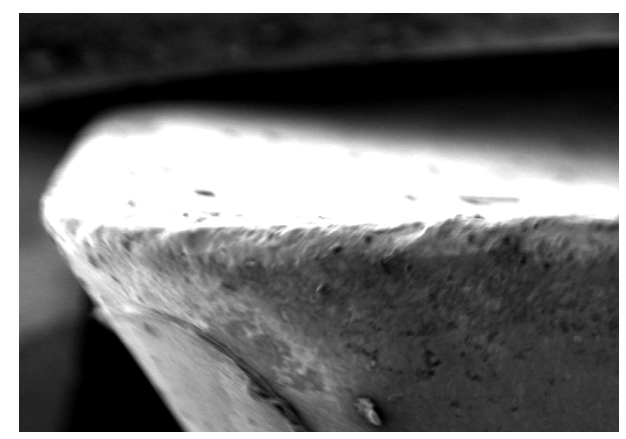

Fig. 10d: Wear experienced at $150 \mathrm{~m} / \mathrm{min}$ of case III $(95 \mathrm{x}$ enlargement.

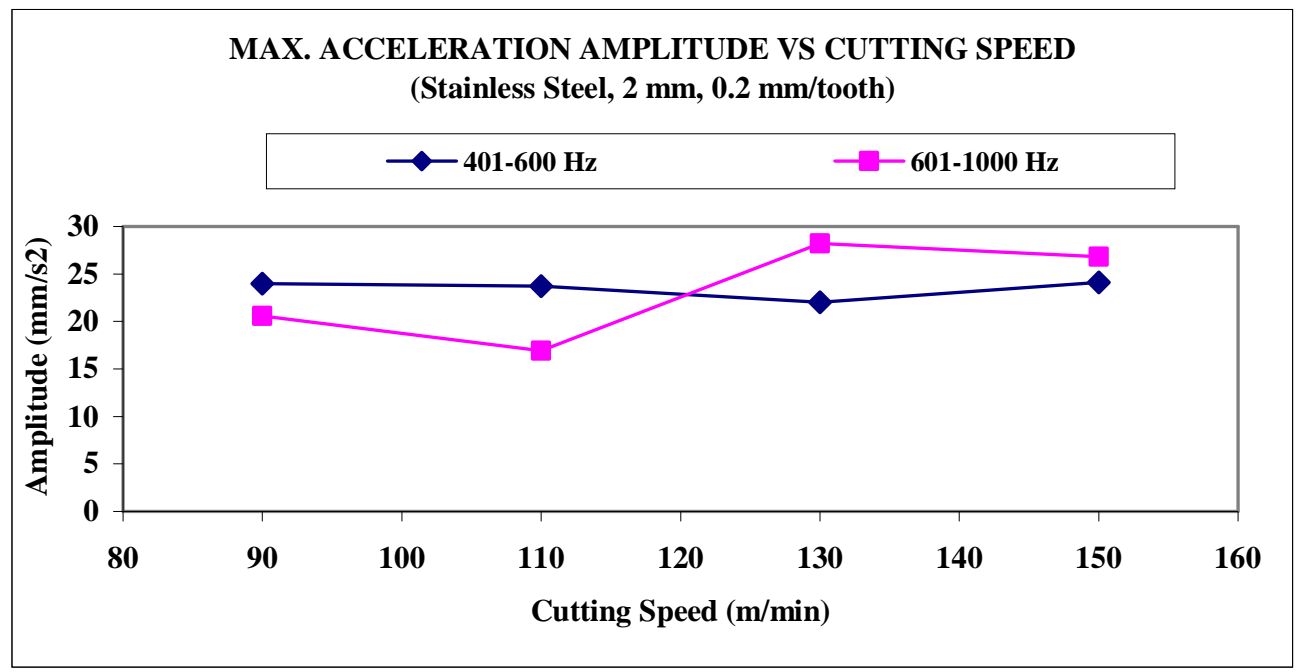

Fig. 11: Influence of the cutting speeds on Peak Acceleration Amplitude in the two frequency ranges for cutting condition IV.

\section{CONCLUSION}

The following conclusions can be drawn from this work:

1. There are peak values of tool life curves, which occur as a result of minimum tool wear intensities. In some cases more than one peak point in tool life curves are observed. These points show deviation from the linear shape of the tool life versus cutting speed curve in the log-log scale.

2. Acceleration amplitudes have the general tendency to be high as cutting speed, feed and depth of cut are increased, but there are minimum points on the curve which correspond to cutting speeds yield minimum tool wear intensities and uniform tool wear.

3. Cutting speed of $110 \mathrm{~m} / \mathrm{min}$ has been found to be the most suitable cutting speed for most of the cutting conditions. 
4. Cutting speeds of $150 \mathrm{~m} / \mathrm{min}$ and above are not recommended for machining for the investigated cutting condition, due to either high intensity of tool wear or high level of vibration.

5. SEM pictures of the worn tool bear evidence of diffusion type wear in most cases, but the occurrence of erratic tool failures are attributed to attrition and brittle breakages of the micro sections of the tool.

6. The recommended cutting conditions, as shown in Table 3, may help achieve optimum results in terms of tool life, machined surface finish, and vibration stability during end milling of stainless steel work pieces.

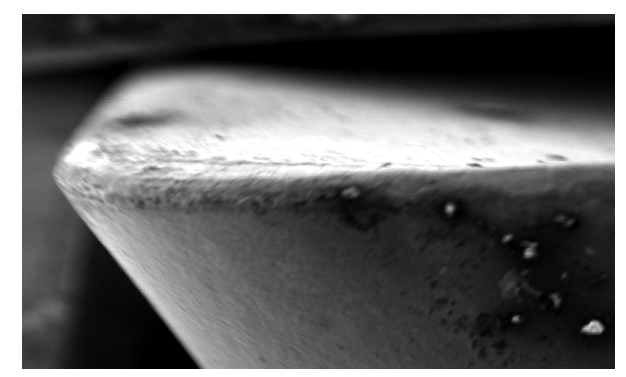

Fig. 12a: Wear experienced at $90 \mathrm{~m} / \mathrm{min}$ of case IV (95 x enlargement).

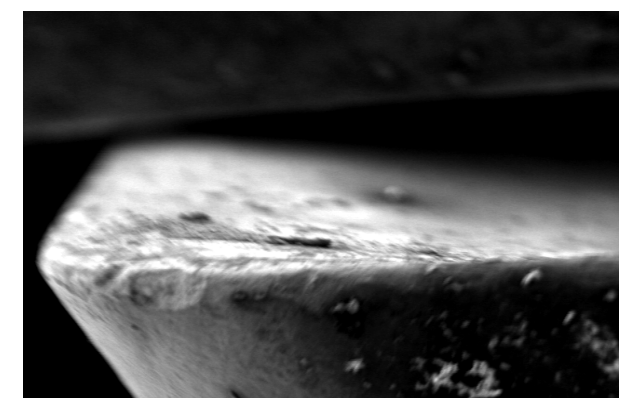

Fig. 12b: Wear experienced at $110 \mathrm{~m} / \mathrm{min}$ of case IV (95 x enlargement).

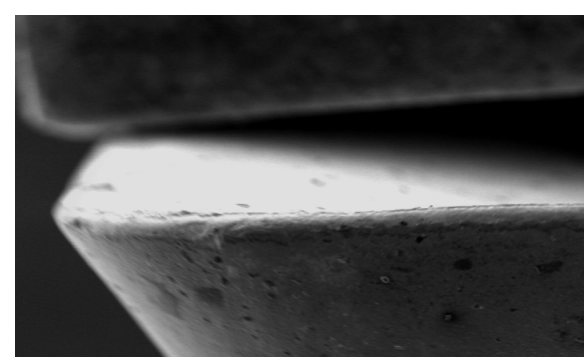

Fig. 12c: Wear experienced at $130 \mathrm{~m} / \mathrm{min}$ of case IV (95 x enlargement). 


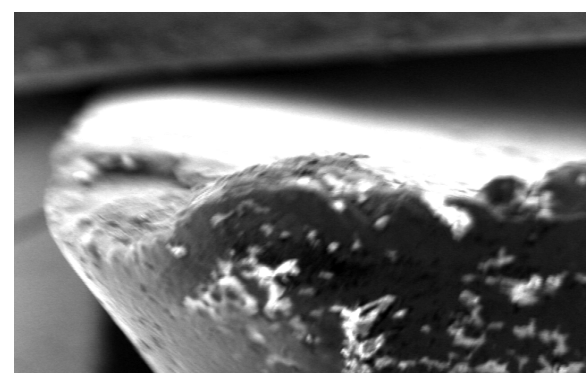

Fig. 12d: Wear experienced at $150 \mathrm{~m} / \mathrm{min}$ of case IV (95 x enlargement).

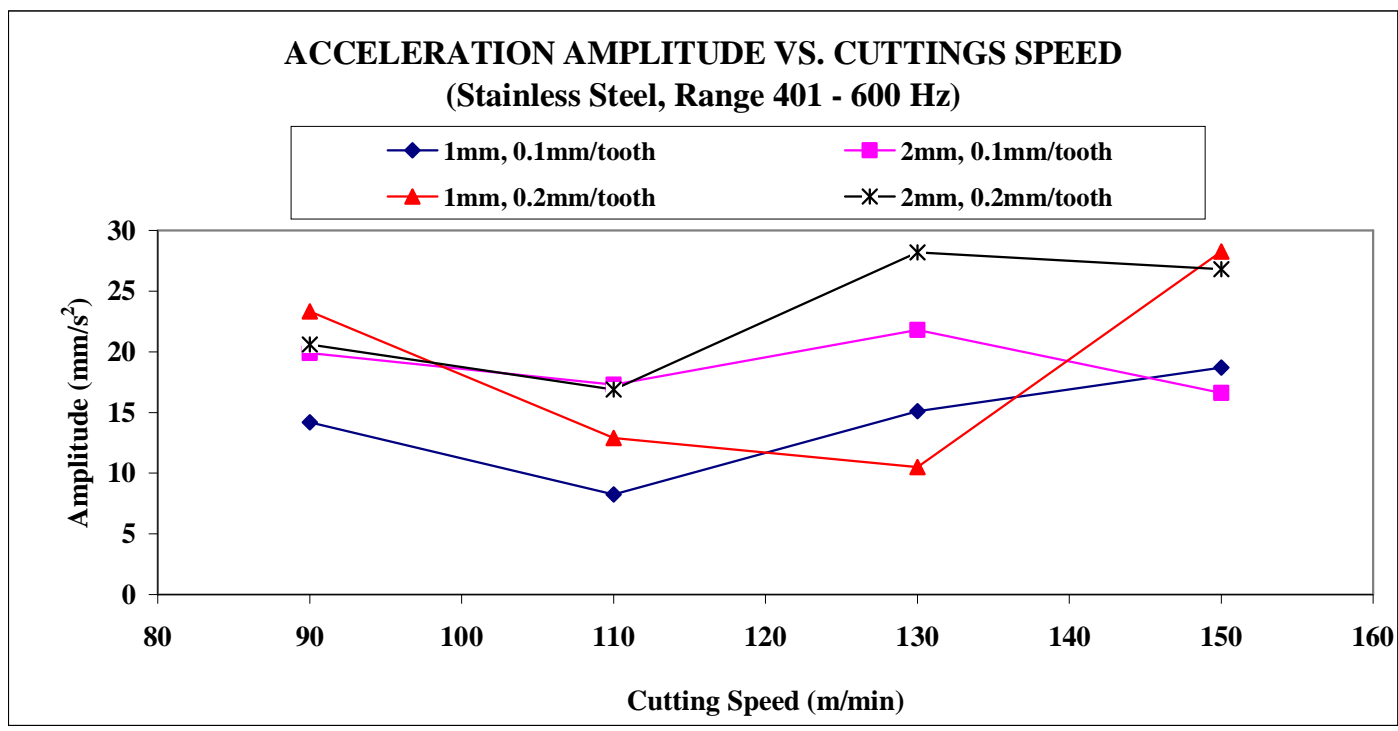

Fig. 13: Peak acceleration amplitude over cutting speeds for different cutting conditions in the frequency range of 401-600 Hz.

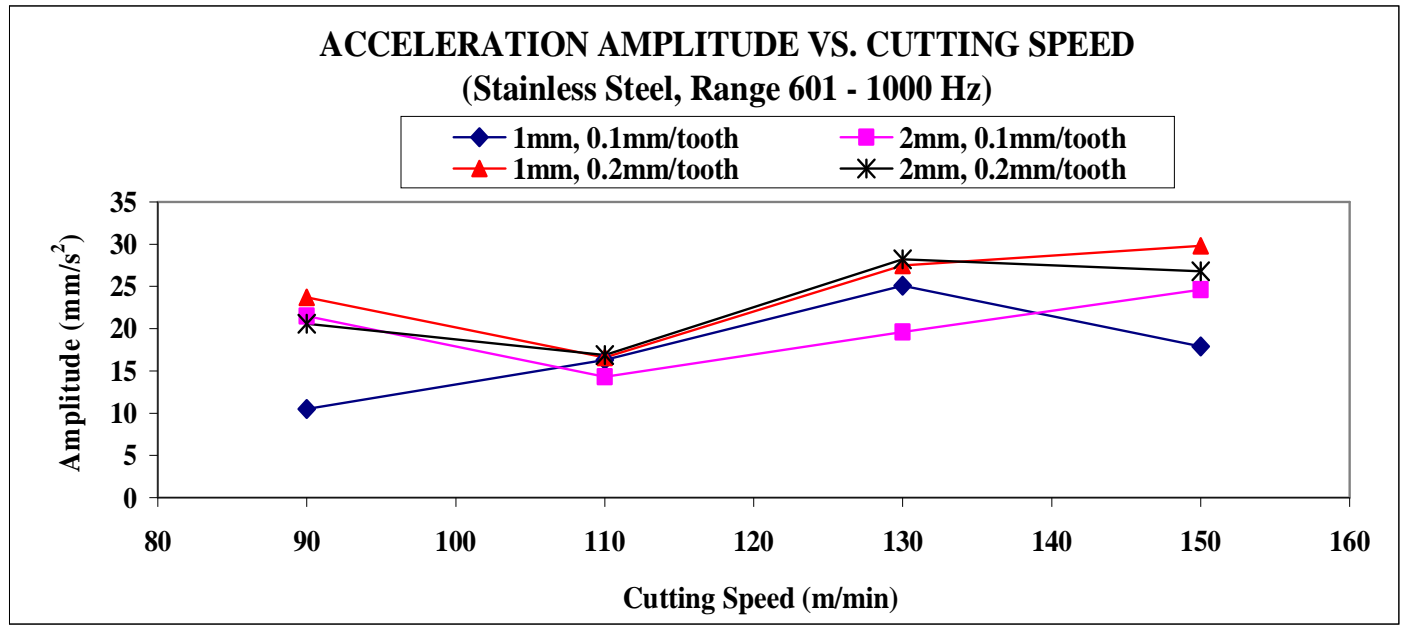

Fig. 14: Peak acceleration amplitude over cutting speeds for different cutting conditions in the frequency range of $601-1000 \mathrm{~Hz}$. 


\section{ACKNOWLEDGEMENT}

The authors are grateful to the Research Centre, International Islamic University Malaysia for funding the research project.

\section{REFERENCES}

[1] A.K.M.N. Amin, "Investigation of the Mechanism of Chatter Formation During Metal Cutting Process", Mech. Engg. Res. Bulletin, 6(1), BUET, Dhaka, pp. 11-18, 1983.

[2] N.V. Talantov, A.K.M.N. Amin and N.P. Chereomushnikov, "Temperature Deformation Laws of Chatter Formation on Metal Cutting Process, Proceedings of the $5^{\text {th }}$ Soviet National Conference", Teplophysika Technologichieskikh Processov", Volgograd (USSR), 1980.

[3] E.M. Trent, "Metal Cutting", Butterworth-Heinemann Ltd., 5 ${ }^{\text {th }}$ edition, 2000.

[4] A.K.M.N. Amin, "Influence of the Characteristics of Machine-Tool-Fixture-Work (MTFW) System on Chatter", Journal of the Institute of Engineers, Bangladesh (IEB), 13(4), Dhaka, 1985.

[5] K. Jemialniak, and A. Windota, "Supression of Self-excited Vibration by Spindle Speed Variation Method”, Int. J. Mach. Tool Des Res. 24, 1984.

[6] A.D. Salha, and S.S. Salhana, "Chatter Effect on vertical Machining Center and Its Machining Quality", Faculty of Engineering, International Islamic University Malaysia, 2000.

\section{BIBLIOGRAPHIES}

Dr. A.K.M. Nurul Amin is currently working as a Professor and Head of the Department of Manufacturing and Materials Engineering at the Faculty of Engineering, International Islamic University Malaysia. Dr. Amin was serving as a Professor and Head of Department of Industrial and Production Engineering, Bangladesh University of Engineering and Technology, Dhaka before joining IIUM. He obtained his M.Sc. degree in Manufacturing Engineering from Volgograd Polytechnic Institute in 1979 and Ph.D. degree from the Georgian Polytechnic Institute in 1982. His areas of research interest are machinability, machine tool chatter and optimization of metal cutting processes.

Mr. Mohd. Imran Feroze is a citizen of Myanmar. He completed his Bachelor of Manufacturing Engineering degree from IIUM, Malaysia in 2001 and is pursuing his Master degree in Manufacturing Engineering at IIUM on part time basis. He is currently employed as an engineer at Petronas, Malaysia.

Mr. M. Arif Elayas is a citizen of Myanmar. He completed his Bachelor of Manufacturing Engineering degree from IIUM, Malaysia in 2001 and is currently pursuing his Master degree in Manufacturing Engineering at IIUM. 